\title{
Manganese and Iron Catalysts in Alkyd Paints and Coatings
}

\author{
Ronald Hage *, Johannes W. de Boer and Karin Maaijen \\ Catexel, Galileiweg 8, 2333 BD Leiden, The Netherlands; hans.de.boer@catexel.com (J.W.B.); \\ karin.maaijen@catexel.com (K.M.) \\ * Correspondence: ronald.hage@catexel.com; Tel.: +31-6-5436-6017 \\ Academic Editor: Duncan H. Gregory \\ Received: 25 March 2016; Accepted: 22 April 2016; Published: 29 April 2016
}

\begin{abstract}
Many paint, ink and coating formulations contain alkyd-based resins which cure via autoxidation mechanisms. Whilst cobalt-soaps have been used for many decades, there is a continuing and accelerating desire by paint companies to develop alternatives for the cobalt soaps, due to likely classification as carcinogens under the REACH (Registration, Evaluation, Authorisation and Restriction of Chemicals) legislation. Alternative driers, for example manganese and iron soaps, have been applied for this purpose. However, relatively poor curing capabilities make it necessary to increase the level of metal salts to such a level that often coloring of the paint formulation occurs. More recent developments include the application of manganese and iron complexes with a variety of organic ligands. This review will discuss the chemistry of alkyd resin curing, the applications and reactions of cobalt-soaps as curing agents, and, subsequently, the paint drying aspects and mechanisms of (model) alkyd curing using manganese and iron catalysts.
\end{abstract}

Keywords: autoxidation; alkyd paint drying; polymerization; cobalt; iron; manganese

\section{Introduction}

Many paint and ink formulations contain alkyd resins as binders to obtain solid coatings after curing [1,2]. Other binders employed include those based on polyesters, polyvinyl, or phenolic resins. Alkyd resins are made of unsaturated fatty acids, polyols, such as glycerol, and polyacids such as phthalic acid. As the main components of alkyd resins are mostly derived from natural oils, such as linseed oil or tung oil, the sources of alkyd resins can thus be considered as being renewable [2]. The paint or ink formulations can either contain organic solvents to dissolve the alkyd resin or water as the solvent. In the latter case, surfactants or emulsifiers are used to ensure stable paint formulations. As legislation in Europe made it necessary to reduce volatile organic compounds (VOC) in paints, there have been shifts to reduce the amount of organic solvents used in the paint formulations, in so-called high-solid solvent-borne formulations, and towards formulations with water as the main solvent in water-borne paints.

To achieve hardening of alkyd-based coatings, radical and autoxidation processes initiated and/or accelerated by transition-metal salts or complexes are necessary. Whilst traditionally cobalt soaps, such as cobalt(II)(2-ethylhexanoate) 2 , have been used as primary driers for radical curing, due to probable classification as carcinogen within the EU under REACH, there has been a surge recently to develop alternative curing catalysts based on alternative transition metals such as manganese and iron. This review will focus on these new developments and, therefore, will not give a comprehensive account on all studies of cobalt soaps for alkyd paint drying. Examples of publications detailing the properties of the cobalt soaps can be found elsewhere $[1,3,4]$.

Besides alkyd resins, other major components typically used in paint formulations include pigments, fillers and a variety of additives, depending on the specific application. Whilst this review 
will not discuss these additives exhaustively, additives such as anti-skinning agents, pigments and fillers will be a subject of further discussion in various sections as they may be interlinked with the performance of the siccatives or indeed the paint formulation itself.

In this review, the chemistry of radical curing processes in relation to alkyd based paints and inks will be discussed first in some detail. Then, several of the mechanistic studies on cobalt soap driers will be discussed, after which publications and patent applications dealing with various classes of paint drying catalysts based on manganese and iron will be highlighted. Although several other alternative driers such as those based on copper containing laccase enzyme [5] or vanadium complexes [6] have been reported, such systems fall outside the scope of the current review. It should be noted that, in the literature, such metal catalysts (both cobalt soaps and alternative alkyd curing catalysts) are also denoted as paint drying catalysts, driers or siccatives. These terms will also be used in this review, although, strictly speaking, the catalysts merely accelerate the autoxidation reactions and do not aid in, for example, evaporation of the solvent as the names could suggest.

\section{Alkyd Resins}

The structure of a typical alkyd resin is given in Figure 1. Alkyd resins typically consist of polymerized polyalcohols, polybasic acids and fatty acids-for example, the structure shown in Figure 1 made from phthalic acid, glycerol and linoleic acid. The drying process of solvent and water borne paints consists of evaporation of the solvent (a physical process) and, subsequently, the hardening process via radical autoxidation reactions takes place. The latter is also known as the chemical or oxidative drying process. These reactions are slow when not accelerated by catalysts.

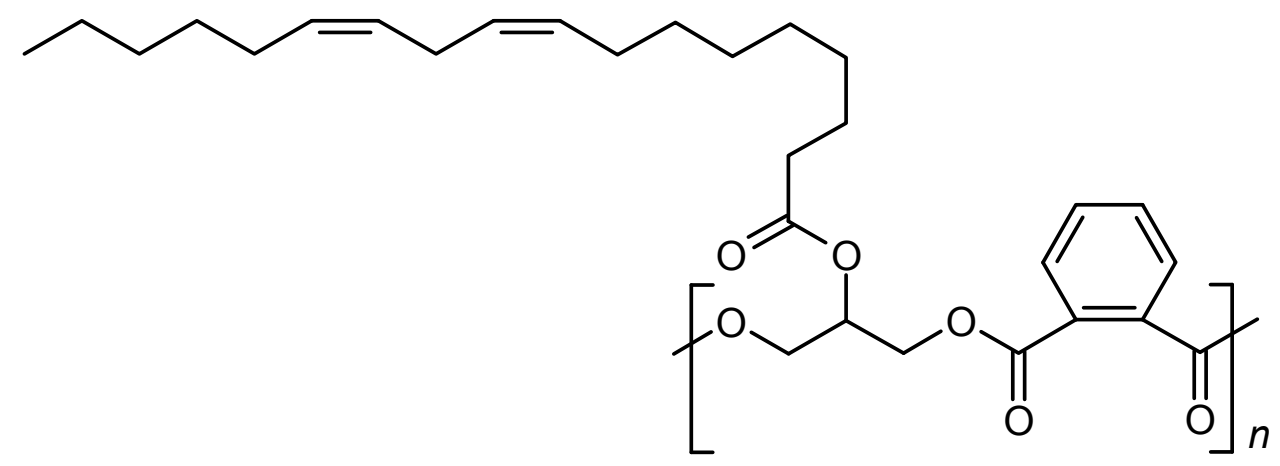

Figure 1. Structure of a typical alkyd resin with linoleic acid as side group.

During the radical curing processes $\mathrm{H}^{\bullet}$-transfer from the double allylic $-\mathrm{CH}_{2}-$ group takes place (Scheme 1) [1,4]. Besides the transition-metal catalysts as discussed below, also, for example, UV-irradiation accelerates these reactions and may be applied in industrial curing processes (e.g., for ink drying) [7]. For paint drying, UV-curing is more limited, as domestic use UV-irradiation is fluctuating too much and, therefore, UV-curing is not reliable enough to give robust performance.

The (catalysed) autoxidation (i.e., curing) of alkyd resins consumes dioxygen and results eventually in the formation of an extended network (i.e., the dried paint or coating) via a complex process in which a range of different reactions take place more or less concomitantly. Redox-active metal compounds may induce allylic $\mathrm{C}-\mathrm{H}$ activation via different pathways. If a lower-valent metal complex reacts with dioxygen, a higher-valent metal ion with bound superoxide may be formed, according to Reaction (1) in Scheme 1. In addition, two metal ions may react with dioxygen forming a peroxy bridged metal complex (not shown in the scheme). The superoxide or peroxide bound to the metal ion(s) can then abstract an $\mathrm{H}^{\bullet}$ from the alkyd substrate (Reaction (2)). Alternatively, a high-valent metal center may abstract a hydrogen atom (or $\mathrm{H}^{+} / \mathrm{e}$ ) from the allylic $\mathrm{CH}_{2}$ group of the alkyd resin (Reaction (3)). In addition, alkoxy or peroxyl radicals that are formed in the other subsequent reactions (vide infra) can react with the alkyd substrate according to Reactions (4) and (5). When $\mathrm{H}^{\bullet}$ abstraction 
takes place from a double allylic $-\mathrm{CH}_{2}$ - group, a conjugated system is often formed and this can react with $\mathrm{O}_{2}$ (Reaction (6)). The peroxyl radical species formed as depicted in Reaction (6) can, for example, abstract $\mathrm{H}^{\bullet}$ radicals from the unreacted alkyd resin, yielding (conjugated) hydroperoxyl $(\mathrm{ROOH})$ species (Reaction (5)).

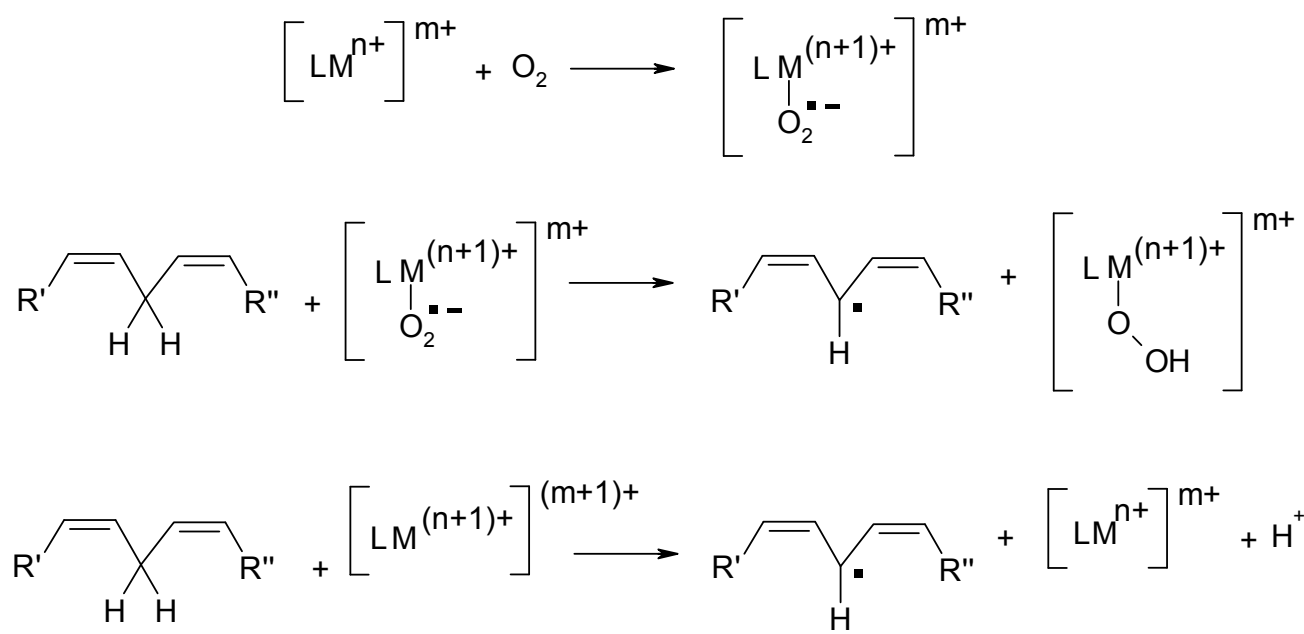<smiles>[R]C=CC/C=C\[R][R6]#CC[R]</smiles>

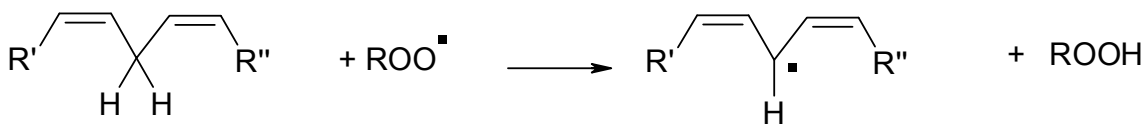

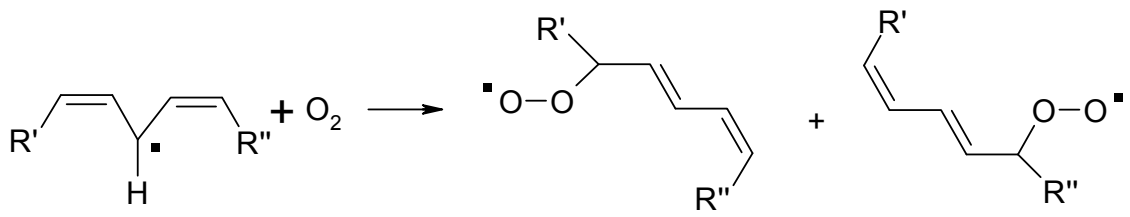

Scheme 1. Examples of reactions during radical curing processes in alkyd resins (L stands for organic ligand bound to metal ion) (Reactions (1)-(6)) [4].

The alkyd resin radical intermediates $\left(\mathrm{R}^{\bullet}, \mathrm{RO}^{\bullet}\right.$, and $\left.\mathrm{ROO} \mathrm{O}^{\bullet}\right)$ also do react further with each other in termination reactions to form various species, such as $\mathrm{R}-\mathrm{R}, \mathrm{R}-\mathrm{O}-\mathrm{R}, \mathrm{R}-\mathrm{OO}-\mathrm{R}$ and also react, for example, with $\mathrm{R}-\mathrm{H}$, dioxygen etc. in propagation reactions. As a lot of these reaction products still contain (poly)unsaturated groups, further reactions may occur as outlined above, leading to larger polymerized networks, observed as a hardened paint or coating layer.

The peroxy radical or alkylhydroperoxide species may also react with the transition-metal species or catalyst to form metal-alkylperoxo species (Reaction (7), Scheme 2). Such adducts are well-known for cobalt, manganese and iron complexes (see [8-11] for some representative examples of characterized metal-alkylperoxo species). These adducts may decompose to form peroxyl or alkoxy radicals (Reactions (8) and (9), respectively) [4]: 


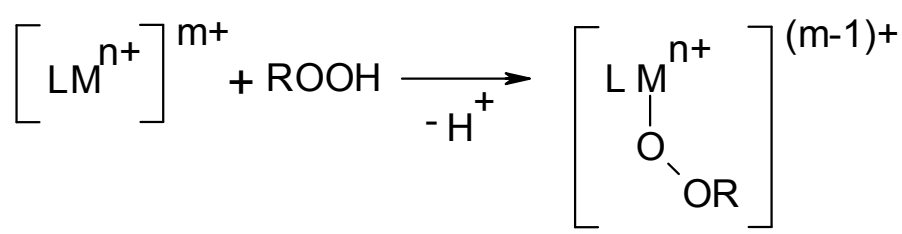

$\left[\mathrm{M}_{\mathrm{O}}^{\mathrm{L}^{\mathrm{n}+}}\right]^{(\mathrm{m}-1)+} \longrightarrow\left[\mathrm{LM}^{(\mathrm{n}-1)+}\right]^{(\mathrm{m}-1)+}+\mathrm{ROO}$

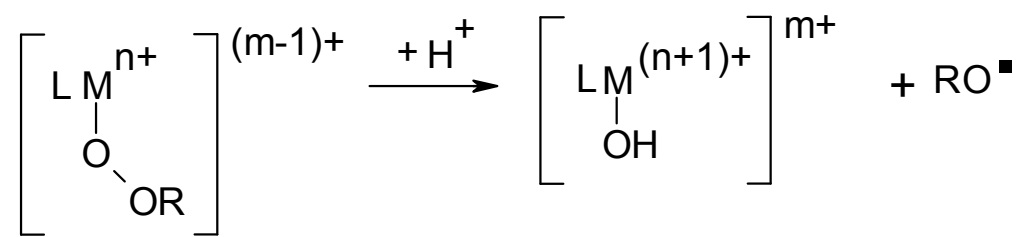

Scheme 2. Reactions showing the formation of peroxyl radicals (8) and alkoxy radicals (9) from a metal-alkylperoxyl intermediate obtained by reaction of the metal complex with an alkylhydroperoxide (7) [4].

These alkoxy and peroxyl radicals may in turn react with unreacted alkyd resins to induce allylic $\mathrm{H}^{\bullet}$ abstraction reactions (Reactions (4) and (5)) or they may react with unreacted alkyd resins or with other radical species to form cross-linked networks as described above. Another type of reaction, which is observed (by olfaction) after having painted a layer of alkyd-resin containing coatings, occurs also: the alkoxy radicals of the alkyd resin may undergo $\beta$-scission reactions, leading to carbon-carbon cleavage reactions and formation of volatile reaction products such as aldehydes (see Scheme 3) [1,4].

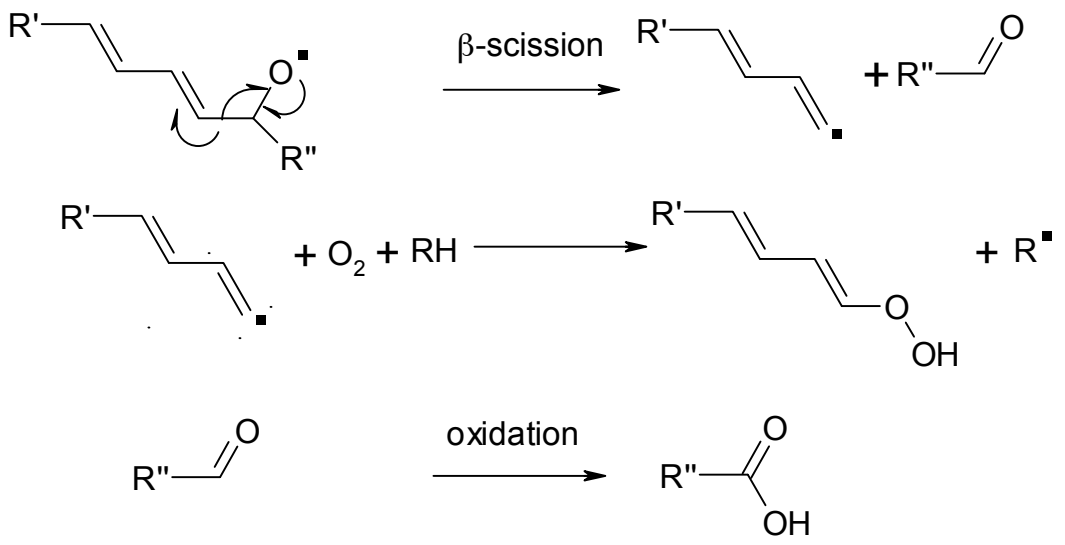

Scheme 3. Example of $\beta$-scission reactions of fatty-acid derived alkoxy radical leading to aldehydes and acids [4].

As will be exemplified in more detail in the different sections on cobalt, manganese and iron based drying catalysts, ethyllinoleate is used regularly as a model compound for alkyd resins to study the above-mentioned reactions. The advantage is that spectroscopic fingerprinting can be more facile, whilst still the main processes as occurring in alkyd resins do occur using this substrate. Further, as this substrate has been used quite widely, it is easier to compare the reactivity of the different catalysts. 


\section{Cobalt Soaps}

Cobalt-soap siccatives are known to cure alkyd-based resins efficiently and many paint and coating formulations have been adapted to attain optimal performance. The most widely used cobalt soap is cobalt(II)(2-ethylhexanoate) ${ }_{2}$ (abbreviated as $\left.\mathrm{Co}^{\mathrm{II}}(2-\mathrm{EH})_{2}\right)$ which is commercially available dissolved in organic solvents at different concentrations (Figure 2) [1,2]. The concentration of the cobalt soap is often expressed at wt \% of cobalt metal in the solution, typically between 6 and $12 \mathrm{wt} \%$. As the molecular weight of $\mathrm{Co}^{\mathrm{II}}(2-\mathrm{EH})_{2}$ is $345 \mathrm{~g} / \mathrm{mol}$ and cobalt $59 \mathrm{~g} / \mathrm{mol}$, the solution contains typically between $35 \mathrm{wt} \%(1 \mathrm{M})$ and $70 \mathrm{wt} \%(2 \mathrm{M})$ of $\mathrm{Co}^{\mathrm{II}}(2-\mathrm{EH})_{2}$. The paint or coating formulator will dilute the $\mathrm{Co}^{\mathrm{II}}(2-\mathrm{EH})_{2}$ solution to about $0.01-0.05 \mathrm{wt} \%$ of cobalt $v$ s. binder in the paint formulation. In addition, often cobalt(II)(neodecanoate) ${ }_{2}$ and cobalt(II)(naphthenate) ${ }_{2}$ are used as well in similar concentration ranges. It should be noted that cobalt naphthenate and cobalt neodecanoate often consist of different isomeric compounds of which the ones depicted Figure 2 are typical ones. More recently, polymers that bind cobalt soaps have been proposed as alternatives to cobalt soaps [12].

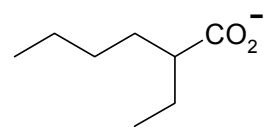

2-EH

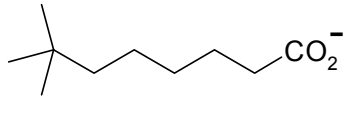

neodecanoate

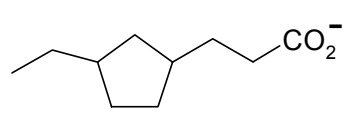

naphthenate

Figure 2. Structures of carboxylates of cobalt soaps used in alkyd resin paints. Both neodecanoate and naphthenate are each mixtures of isomers and only a typical component present in neodecanoate and naphthenate is shown, respectively.

Besides the cobalt soap, which is a primary drier, i.e., directly involved in the radical curing of the alkyd resins, other metal-based additives are also employed often [3,4]. These so-called secondary and auxiliary driers enhance the hardness of the coating and improve through-drying of the paint. Examples of secondary driers are zirconium, strontium, calcium, cerium, and barium soaps. It is thought that these metals bind to different carboxylic acid moieties from the binder, thereby enhancing the strength of the intermolecular networks [1]. In addition, driers such as $\mathrm{Ca}(2-\mathrm{EH})_{2}$ or $\mathrm{Ba}(2-\mathrm{EH})_{2}$ are used to reduce adsorption of the siccative on solid particals. Paint formulations often contain pigments or fillers that may adsorb part of the cobalt soaps, thereby reducing the rate of paint drying, also known as loss-of-dry. Addition of calcium or barium soaps to the paint formulation containing the pigments and fillers, and especially before adding the cobalt soap, reduces the loss-of-dry effects of the pigments and fillers.

As the cobalt soap accelerates the curing of the alkyd resins when applied on a substrate, it may also happen during storage of the paint. Premature curing may be apparent when a skin or lump of polymerized paint is present in an (old) tin of paint. To circumvent undesired curing prior to application of the paint to a surface, often so-called anti-skinning agents are added to the paint formulation. Various types of anti-skinning agents exist. Volatile oxime-based compounds bind reversibly to the cobalt ions, preventing reaction with the unsaturated alkyd resin in the tin. When applied to the surface, the volatile oxime evaporates, shifting the equilibrium from oxim-bound cobalt towards free cobalt ion, thereby allowing the redox-active cobalt ion to react with the alkyd resin and $\mathrm{O}_{2}$, as discussed above. Furthermore, these oximes may directly trap radicals that might be formed [13]. The most widely used oxime as anti-skinning agent is methylethylketoxime (MEKO). Phenol- or amine-based anti-skinning agents are sometimes employed as well. These latter two classes of anti-skinning agents are more considered as classical anti-oxidants that trap efficiently alkoxy and alkylperoxyl radicals. A disadvantage is that these compounds will also function as anti-oxidants after application of the paint to a surface, thereby increasing the time needed for the paint to dry. Careful optimization of the levels of such anti-oxidants are needed to attain the right level of anti-skinning behavior in the paint formulation vs. drying time on the surface. 
Whilst cobalt soap siccatives were employed initially in solvent-borne paints, more recently, alkyd formulations/emulsions in water with water emulsifiable cobalt based driers were developed. Relatively less information has been generated on the cobalt-induced polymerization processes during drying of water-borne (WB) alkyd paints, but an interesting paper by Oyman et al. described the reactivity of various emulsified model substrates for the alkyd resins with $\mathrm{O}_{2}$ catalyzed by a cobalt soap emulsion [14]. Methyloleate, methyllinolenate, and ethyllinoleate were used as model substrates. Here, only the latter substrate (ethyllinoleate) will be discussed, as it resembles well the typical alkyd resins and has also been used in many other studies (vide infra). When adding the cobalt soap emulsion to the ethyllinoleate emulsion, no reaction with the substrate takes place until water had evaporated. Raman and FTIR spectroscopy showed that first the non-conjugated $\mathrm{CH}=\mathrm{CH}-\mathrm{CH}_{2}-\mathrm{CH}=\mathrm{CH}$ group of ethyllinoleate converts to conjugated $\mathrm{C}=\mathrm{C}-\mathrm{C}=\mathrm{C}$ groups (it should be noted that this conversion takes place after $\mathrm{H}^{\bullet}$ abstraction of the labile allylic $\mathrm{CH}_{2}$ group has taken place, as shown in Reactions (2)-(5) in Scheme 1; Reaction (6) shows formation of conjugated $C=C-C=C$ species). Subsequently, slowly a decrease in intensity of Raman bands originating from the conjugated double $C=C$ groups in the substrate was observed. This has been assigned to further propagation and/or $\beta$-scission reactions. In addition, it was suggested that the depletion of the conjugated bonds is mostly associated with addition reactions of radical intermediates (such as $\mathrm{RO}^{\bullet}$ and $\mathrm{ROO}^{\bullet}$ ) to the double bonds, as also noted by Muizebelt and co-workers [15]. It was further shown that the rate of change of the peak intensity of the (initial) cis- $\mathrm{C}=\mathrm{CH}$ stretching vibration $v$ s. time is quite similar to the one observed in solvent-borne (SB) paints [16], which led to the conclusion that, in WB paints, the type of reactivity induced by the cobalt soap emulsion is similar to that in SB paints [14].

\section{Manganese Catalysts}

\subsection{Manganese Carboxylates}

Since from a toxicology point of view, manganese compares favorably to cobalt, manganese(II)(2-ethylhexanoate) ${ }_{2}$ (abbreviated as $\mathrm{Mn}^{\mathrm{II}}(2-\mathrm{EH})_{2}$ ) has been applied in various paint and ink formulations [1]. In general, the level of $\mathrm{Mn}^{\mathrm{II}}(2-\mathrm{EH})_{2}$ used is higher than that of $\mathrm{Co}^{\mathrm{II}}(2-\mathrm{EH})_{2}$ in paint and ink formulations, because the alkyd polymerization activity of manganese soap is less efficient than that of cobalt soap [3]. As also intensely colored manganese(III) ions may be present in the manganese soaps or may be formed when mixing manganese soaps into the paint, high levels of manganese soaps cannot be used in white or light-colored paint formulations. Sometimes manganese soaps are used in combination with cobalt driers to enable the reduction of the level of both the cobalt and the manganese soap. Significant enhancement of activity of the manganese soap is also obtained by addition of amine-based ligands allowing the paint formulator to reduce the level of manganese thereby reducing the effect of the color of higher valent Mn ions (vide infra).

Polymers have been synthesized that are based on manganese-carboxylates and they have been patented as alternative paint drying siccatives [17]. The use of the polymeric material containing manganese carboxylates has been claimed to increase solubility in solvent borne paint or ink formulations whilst at the same time reduce the leaching manganese ions in aqueous solutions. Comparing the alkyd-paint drying activity using a Mn-containing polymer at the same level of Mn as $\mathrm{Mn}^{\mathrm{II}}(2-\mathrm{EH})_{2}$ showed a significantly better drying activity for the Mn-polymer. This has been attributed to a better distribution of the $\mathrm{Mn}$ ions due to the co-polymerization of the functional groups of the Mn-polymer with the alkyd resins. Interestingly, carrying out water-solublity tests to measure the release of manganese ions in water when adding the polymer in water, showed that the Mn leaching of the polymer was less than $0.5 \mathrm{mg} / \mathrm{L}$, whilst that of $\mathrm{Mn}^{\mathrm{II}}(2-\mathrm{EH})_{2}$ was $140 \mathrm{mg} / \mathrm{L}$. It should be noted that similar polymers were also developed for Co-based paint drying, and there a considerably higher extent of cobalt leaching was measured [12]. Without further detailed publications on the mechanism, it is unclear why differences with respect to metal ion leaching (Co vs. Mn) would be obtained. 


\subsection{Manganese Complexes}

\subsubsection{Manganese Bipyridine Catalysts}

Improved paint or ink drying activity (compared to $\left.\mathrm{Mn}^{\mathrm{II}}(2-\mathrm{EH})_{2}\right)$ is obtained when 2,2'-bipyridine (bpy) or 1,10-phenanthroline (phen) (Figure 3) is added to the paint formulation containing $\mathrm{Mn}^{\mathrm{II}}(2-\mathrm{EH})_{2}$ [4]. As these bidentate ligands are in general efficient binders to transition-metal ions, it has been assumed that Mn complexes with these ligands are formed in situ. More detailed investigations were conducted by Bouwman and co-workers, who modeled experiments on the disappearance of ethyllinoleate as followed by FTIR (Fourier Transform Infrared Spectroscopy) [18]. It was shown that the use of $\mathrm{Mn}^{\mathrm{II}}(2-\mathrm{EH})_{2}$ exhibits a long induction period of $100 \mathrm{~min}$ before ethyllinoleate reacts with $\mathrm{O}_{2}$. Upon addition of 0.5 molar equivalent of bpy, the induction period was reduced to $10 \mathrm{~min}$ and a similar reactivity as found for $\mathrm{Co}^{\mathrm{II}}(\mathrm{EH})_{2}$ was obtained. In the same paper, the synthesis and characterization by $\mathrm{X}$-ray of a tetranuclear $\left[\mathrm{Mn}^{\mathrm{II}}{ }_{2}{ }_{2} \mathrm{Mn}^{\mathrm{III}}, \mathrm{III}{ }_{2}(\mathrm{bpy})_{2}(\mu-O)_{2}(\mu-2-\mathrm{EH})_{6}\right]$ complex obtained from $\mathrm{Mn}^{\mathrm{II}}(\mathrm{EH})_{2}$ and bpy is described. This compound exhibited similar behavior as the mixture of $\mathrm{Mn}^{\mathrm{II}}(\mathrm{EH})_{2}$ and bpy, i.e., a short lag-phase of $10 \mathrm{~min}$ and fast depletion of the substrate. It should be noted that, obviously, isolation and crystallization of this tetranuclear compound does not prove that such species are formed or involved in the paint drying activity; however, these results might indicate that this species could be a kinetically competent precursor to the catalytically active species. More recently, it has been shown that addition of bidentate bpy and phen ligands increase the activity of Mn soaps towards oxidative polymerization of linseed oil as well [19].
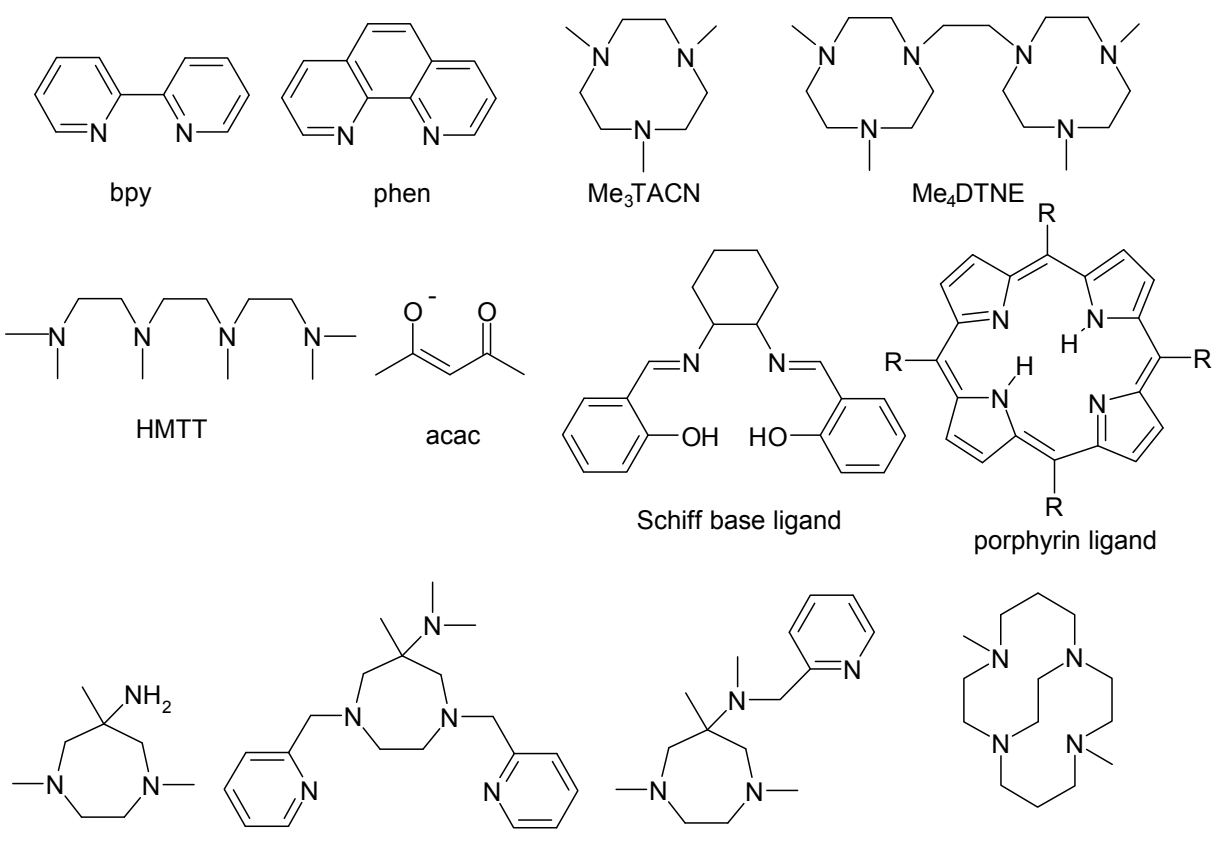

Examples of 1,4-diazacycloheptane ligands

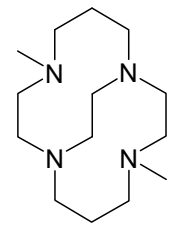

Bcyclam

Figure 3. Ligands exhibiting paint drying activity with Mn salts or as Mn-ligand complexes discussed in the text: 2,2'-bipyridine (bpy), 1,10-phenanthroline (phen), 1,4,7-trimethyl-1,4,7-triazacyclononane $\left(\mathrm{Me}_{3} \mathrm{TACN}\right), 1,2-$ bis(4,7-dimethyl-1,4,7-triazacyclononan-1-yl)-ethane (Me $\left.4 \mathrm{DTNE}\right), N, N, N^{\prime}, N^{\prime \prime}, N^{\prime \prime \prime}, N^{\prime \prime \prime}$ hexamethyltriethylenetetraamine (HMTT), acetylacetonate (acac), $N, N^{\prime}$-bis(salicylidene) cyclohexylenediamine (Schiff-base ligand), 5,10,15,20-tetrakisphenylporphyrin and 5,10,15,20-tetrakis ( $4^{\prime}$-methoxyphenyl)porphyrin ( $\mathrm{R}$ = phenyl and 4-methoxyphenyl, respectively; porphyrin ligand), 6-amino- 1 , 4,6-trimethyl-1, 4-diazacycloheptane, 6-dimethylamino-1,4-bis(pyridine-2-ylmethyl)-6-methyl-1, 4-diazacycloheptane, 1,4,6-trimethyl-6\{N-pyridin-2-ylmethyl)- $N$-methylamino\}-1,4-diazacycloheptane (examples of 1,4-diazacycloheptane based ligands), 4,11-dimethyl-1,4,8,11-tetraazabicyclo[6.6.2] hexadecane (Bcyclam). 


\subsubsection{Manganese Acetylacetonate Catalysts}

Manganese(acetylacetonate) $)_{3}\left(\left[\mathrm{Mn}^{\mathrm{III}}(\mathrm{acac})_{3}\right]\right.$ (Hacac = acetylacetone; Figure 3$)$ has been studied for the oxidation of ethyllinoleate (a model substrate for alkyd resins) by using FTIR [20]. Purified ethyllinoleate was used to exclude hydroperoxide impurities in the substrate. It was shown that $\left[\mathrm{Mn}^{\mathrm{III}}(\mathrm{acac})_{3}\right.$ ] gave a much shorter lag phase than $\mathrm{Mn}^{\mathrm{II}}(2-\mathrm{EH})_{2}(<100$ vs. $700 \mathrm{~s})$. After the lag-phase, the rate of ethyllinoleate depletion was still lower than found for $\mathrm{Co}^{\mathrm{II}}(2-\mathrm{EH})_{2}\left(1 \times 10^{-3}\right.$ vs. $\left.3 \times 10^{-3} \mathrm{~min}^{-1}\right)$ Interestingly, addition of one molar equivalent of bpy to $\left[\mathrm{Mn}^{\mathrm{III}}(\mathrm{acac})_{3}\right]$ gave a further shortening of the lag-phase to $30 \mathrm{~s}$ and an increased rate of ethyllinoleate depletion $\left(4 \times 10^{-3} \mathrm{~min}^{-1}\right)$, surpassing the activity of $\mathrm{Co}^{\mathrm{II}}(2-\mathrm{EH})_{2}$. It was suggested that $\left[\mathrm{Mn}^{\mathrm{III}}(\mathrm{acac})_{3}\right]$ reacts with ethyllinoleate via a $\mathrm{H}^{\bullet}$ abstraction process, leading to formation of ethyl linoleate radical intermediate and $\left[\mathrm{Mn}^{\mathrm{II}}(\mathrm{acac})_{2}\right]+$ Hacac (see Reaction (3) in Scheme 1). The ethyllinoleate radical reacts with $\mathrm{O}_{2}$, thereby forming the peroxyl radical of ethyl linoleate, which then reacts further with ethyllinoleate (Reactions (6) and (5), respectively, in Scheme 1). It is thought that the addition of bpy leads to stabilization of the reduced manganese species, thereby facilitating the initial radical abstraction process.

A follow-up study was done by Oyman et al., using the same catalyst with (unpurified) ethyl linoleate to study the polymerization process in more detail [21]. FTIR experiments were done to follow the changes in the $C=C$ vibrations. It was shown that conjugated $C=C$ intermediates are formed (Reaction (6) in Scheme 1) [21]. This conversion was shown to be much slower for [ $\left.\mathrm{Mn}^{\mathrm{III}}(\mathrm{acac})_{3}\right]$ than when $\mathrm{Co}^{\mathrm{II}}(\mathrm{EH})_{2}$ was employed. The addition of one molar equivalent of bpy to [ $\left.\mathrm{Mn}^{\mathrm{III}}(\mathrm{acac})_{3}\right]$ accelerated this conversion, in agreement with the study described above. $\mathrm{O}_{2}$ uptake experiments supported above-mentioned findings that $\left[\mathrm{Mn}^{\mathrm{III}}(\mathrm{acac})_{3}\right]$ reacts much slower than $\mathrm{Co}^{\mathrm{II}}(\mathrm{EH})_{2}$, whilst upon addition of bpy, the intial rate of $\mathrm{O}_{2}$ uptake was higher than when $\mathrm{Co}^{\mathrm{II}}(2-\mathrm{EH})_{2}$ was employed. In addition, the amount of peroxide formed over time was measured. When $\mathrm{Co}^{\mathrm{II}}(2-\mathrm{EH})_{2}$ was employed a steady increase of the amount of $\mathrm{ROOH}$ was measured till $35 \mathrm{~h}$, after which it decreased again. Using $\left[\mathrm{Mn}^{\mathrm{III}}(\mathrm{acac})_{3}\right]$ yielded more $\mathrm{ROOH}$ initially at a similar rate, but continued to increase the $\mathrm{ROOH}$ level for a much longer time $(100 \mathrm{~h})$. Addition of bpy to [ $\left.\mathrm{Mn}^{\mathrm{III}}(\mathrm{acac})_{3}\right]$ led to a different behavior: the maximum amount of $\mathrm{ROOH}$ was reached already after $10 \mathrm{~h}$, after which it started to decrease, and the amount of $\mathrm{ROOH}$ formed was much lower than observed for [ $\left.\mathrm{Mn}^{\mathrm{III}}(\mathrm{acac})_{3}\right]$ without bpy. The rate of oligomerization of the substrate appeared to be best for $\mathrm{Co}^{\mathrm{II}}(2-\mathrm{EH})_{2}$, but again the data indicated that the addition of bpy to $\left[\mathrm{Mn}^{\mathrm{III}}(\mathrm{acac})_{3}\right]$ leads to a clear increase of reactivity compared to $\left[\mathrm{Mn}^{\mathrm{III}}(\mathrm{acac})_{3}\right]$. During these oxidation processes, $\beta$-scission reactions also took place, leading to the formation of volatile aldehydes, such as pentanal and hexanal (Reaction (10) in Scheme 3). [Mn ${ }^{\mathrm{III}}(\mathrm{acac})_{3}$ ] with bpy was again much more active to form these aldehydes than $\mathrm{Co}^{\mathrm{II}}(\mathrm{EH})_{2}$ and $\left[\mathrm{Mn}^{\mathrm{III}}(\mathrm{acac})_{3}\right]$ without bpy.

In addition, paint drying experiments were done using $\left[\mathrm{Mn}^{\mathrm{III}}(\mathrm{acac})_{3}\right]$ and bpy on various alkyd-based formulations [22]. It was shown that at relatively high levels of Mn (0.1 wt \%) the alkyd-paint drying activity of $\left[\mathrm{Mn}^{\mathrm{III}}(\mathrm{acac})_{3}\right]$ was clearly better than that of Mn-bpy (Section 4.2.1) (surface dry time of 6 and $13 \mathrm{~h}$, respectively) and slightly slower than when using CoII $(\mathrm{EH})_{2}$ used at $0.08 \mathrm{wt} \% \mathrm{Co}$ (surface dry time of $5 \mathrm{~h}$ ). In contrast to the outcome of the model experiments, addition of bpy to [ $\left.\mathrm{Mn}^{\mathrm{III}}(\mathrm{acac})_{3}\right]$ did not lead to a faster drying activity. In addition, the hardness of the dried coating appeared to be less than in the absence of bpy, which may be related to the above-mentioned finding that $\beta$-scission reactions may be more prominent for the mixture of $\left[\mathrm{Mn}^{\mathrm{III}}(\mathrm{acac})_{3}\right]$ and bpy. The examples in this patent application [22] showed that the $\left[\mathrm{Mn}^{\mathrm{III}}(\mathrm{acac})_{3}\right]$ and $\left[\mathrm{Mn}^{\mathrm{III}}(\mathrm{acac})_{3}\right] / \mathrm{bpy}$ catalysts led to less skinning than $\mathrm{Mn}-\mathrm{bpy}, \mathrm{Mn}^{\mathrm{II}}(2-\mathrm{EH})_{2}$ and $\mathrm{Co}^{\mathrm{II}}(2-\mathrm{EH})_{2}$. This is probably related to reversible binding of acetylacetonate to $\mathrm{Mn}$, thus reducing the activity towards radical formation and autoxidation in the paint formulation. When applying on the surface, Hacac can evaporate and render the manganese ions active towards radical-induced alkyd curing. 


\subsubsection{Manganese 1,4,7-Triazacyclononane Catalysts}

Manganese complexes with 1,4,7-trimethyl-1,4,7-triazacyclononane (Me 3 TACN, Figure 3) and 1,2-bis(4,7-dimethyl-1,4,7-triazacyclononan-1-yl)-ethane ( $\mathrm{Me}_{4} \mathrm{DTNE}$, Figure 3) as ligand have been studied as well-defined complexes and as mixtures of manganese salts with these ligands.

$\left[\mathrm{Mn}^{\mathrm{IV}, \mathrm{IV}}{ }_{2}(\mu-\mathrm{O})_{3}\left(\mathrm{Me}_{3} \mathrm{TACN}\right)_{2}\right]\left(\mathrm{PF}_{6}\right)_{2}$ is active towards ethyllinoleate oxidation as shown by IR and Raman measurements, with an activity higher than that of $\mathrm{Mn}^{\mathrm{II}}(2-\mathrm{EH})_{2}$, but lower than that of $\mathrm{Co}^{\mathrm{II}}(2-\mathrm{EH})_{2}$ [23]. The addition of $N, N, N^{\prime}, N^{\prime \prime}, N^{\prime \prime \prime}, N^{\prime \prime \prime}$-hexamethyltriethylenetetraamine (HMTT) leads to faster conversions of the substrate, which has been assigned in that paper to improved compatibility of the substrate and the poorly soluble $\left[\mathrm{Mn}^{\mathrm{IV}, \mathrm{IV}}{ }_{2}(\mu-\mathrm{O})_{3}\left(\mathrm{Me}_{3} \mathrm{TACN}\right)_{2}\right]\left(\mathrm{PF}_{6}\right)_{2}$. Experiments showed that the formation and subsequent depletion of alkylhydroperoxides was also accelerated by the addition of HMTT. In the same paper, the rate and extent of oligomerization of ethyllinoleate by using size exclusion chromatography was also studied. In addition, the improved reactivity when adding HMTT was noted. It was concluded that $\left[\mathrm{Mn}^{\mathrm{IV}, \mathrm{IV}}{ }_{2}(\mu-\mathrm{O})_{3}\left(\mathrm{Me}_{3} \mathrm{TACN}\right)_{2}\right]\left(\mathrm{PF}_{6}\right)_{2}$ in combination with polyamines may be a commercially attractive alternative to $\mathrm{Mn}^{\mathrm{II}}(2-\mathrm{EH})_{2}$ and $\mathrm{Co}^{\mathrm{II}}(2-\mathrm{EH})_{2}$.

The same catalyst was shown to exhibit drying activity in short oil and long oil solvent borne (SB) alkyd paint formulations, as well as in water-borne alkyd-emulsion paints (short and long oil alkyd resins refer to the type of oil used in the resin) [24]. In the short oil SB paint, the Mn-Me 3 TACN catalyst showed a similar drying activity as $\mathrm{Co}^{\mathrm{II}}(2-\mathrm{EH})_{2}$ (the latter mixed with the secondary driers $\mathrm{Ca}(2-\mathrm{EH})_{2}$ and $\left.\mathrm{Sr}(2-\mathrm{EH})_{2}\right)$ and significantly better activity than when using $\mathrm{Mn}^{\mathrm{II}}(2-\mathrm{EH})_{2}$. Furthermore, it was noted that the color change of the paint due to the addition of the red manganese catalyst was acceptable. In addition, in the long oil alkyd paint, a good performance was noted (through-drying time was much shorter $(5 \mathrm{~h})$ than the Co-soap mixture ( $>20 \mathrm{~h}$ ) with a slightly lower hardness value). In WB alkyd paints, drying activity was also observed (similar to that of the commercial cobalt-based siccative), but now with increased coloring of the paint and much lower hardness values than obtained for the Co siccative. The same paint formulations have been used to study the changes of the intensities $\mathrm{C}=\mathrm{C}$ bond vibration at $1650 \mathrm{~cm}^{-1}$. In the $\mathrm{SB}$ alkyd formulations, $\mathrm{Co}{ }^{\mathrm{II}}(2-\mathrm{EH})_{2}$ showed fast $\mathrm{C}=\mathrm{C}$ depletion at the surface and much lower rate of $\mathrm{C}=\mathrm{C}$ depletion deeper in the film. $\mathrm{Mn}^{\mathrm{II}}(2-\mathrm{EH})_{2}$ and $\left[\mathrm{Mn}^{\mathrm{IV}, \mathrm{IV}}{ }_{2}(\mu-\mathrm{O})_{3}\left(\mathrm{Me}_{3} \mathrm{TACN}\right)_{2}\right]\left(\mathrm{PF}_{6}\right)_{2}$ exhibited lower surface activity than was found for $\mathrm{Co}^{\mathrm{II}}(2-\mathrm{EH})_{2}$ but did show much better activity towards the deep layer conversion. Similar observations regarding differences in drying rates at the surface $v s$. deeper in the film have been made by Erich and co-workers [25].

A continuation of the studies on the reactivity of $\left[\mathrm{Mn}^{\mathrm{IV}, \mathrm{IV}}{ }_{2}(\mu-\mathrm{O})_{3}\left(\mathrm{Me}_{3} \mathrm{TACN}\right)_{2}\right]\left(\mathrm{PF}_{6}\right)_{2}$ towards ethyllineolate (EL) oxidation in the absence and presence of HMTT was carried out using head-space GC analyses for the determination of volatile reaction products (such as hexanal and heptanal) [26]. The $\mathrm{Mn}-\mathrm{Me}_{3} \mathrm{TACN}$ catalyst itself showed a low and slow conversion of EL towards hexanal as compared to $\mathrm{Co}^{\mathrm{II}}(2-\mathrm{EH})_{2}$. Upon addition of HMTT to $\left[\mathrm{Mn}^{\mathrm{IV}, \mathrm{IV}}{ }_{2}(\mu-\mathrm{O})_{3}\left(\mathrm{Me}_{3} \mathrm{TACN}\right)_{2}\right]\left(\mathrm{PF}_{6}\right)_{2}$, the reactivity was greatly enhanced, which has been linked to the earlier studies on enhanced formation of alkoxy radicals when HMTT was included in the formulation [26]. In the same paper, electrospray MS was also used to study the reactivity between $\left[\mathrm{Mn}^{\mathrm{IV}, \mathrm{IV}}{ }_{2}(\mu-\mathrm{O})_{3}\left(\mathrm{Me}_{3} \mathrm{TACN}\right)_{2}\right]\left(\mathrm{PF}_{6}\right)_{2}$ and ${ }^{t} \mathrm{BuOOH}$ [26]. Various new signals were observed that were assigned to mononuclear and dinuclear $\mathrm{Mn}^{\mathrm{III}}$ complexes. No further evidence using other spectroscopic techniques on the nature of these species was given in the paper, so the conclusions given should be treated with caution (mass spectrometry analyses on reactive intermediates metal complexes may lead to spurious results as oxidation, reduction or further reactions may occur in the spectrometer) [26]. The authors proposed that reaction of $\left[\mathrm{Mn}^{\mathrm{IV}, \mathrm{IV}}{ }_{2}(\mu-O)_{3}\left(\mathrm{Me}_{3} \mathrm{TACN}_{2}\right]\left(\mathrm{PF}_{6}\right)_{2}\right.$ and ${ }^{t} \mathrm{BuOOH}$ leads first to the formation of a mixed-valence $\mathrm{Mn}^{\mathrm{III}} \mathrm{Mn}^{\mathrm{IV}}$ species and ${ }^{t} \mathrm{BuOO}^{\bullet}$ radical. In the second step, the mixed-valence species can react with another ${ }^{\mathrm{t}} \mathrm{BuOOH}$ molecule to form either the original compound (with formation of $\mathrm{RO}^{\bullet}$ ) or to form another dinuclear $\mathrm{Mn}^{\mathrm{III}} \mathrm{Mn}^{\mathrm{III}}$ species and ${ }^{t} \mathrm{BuOO}^{\bullet}$.

In patents filed more recently, it was claimed that $\left[\mathrm{Mn}^{\mathrm{III}, \mathrm{III}}{ }_{2}(\mu-\mathrm{O})\left(\mu-\mathrm{RCO}_{2}\right)_{2}\left(\mathrm{Me}_{3} \mathrm{TACN}\right)_{2}\right]^{2+}$ complexes are also active to dry paint [27]. In the examples, it was shown that two of these complexes 
(with benzoate and 2,6-difluorobenzoate as bridging ligands) showed faster paint drying activity $(3 \mathrm{~h})$ than observed when using $\left[\mathrm{Mn}^{\mathrm{IV}, \mathrm{IV}_{2}}(\mu-\mathrm{O})_{3}\left(\mathrm{Me}_{3} \mathrm{TACN}\right)_{2}\right]\left(\mathrm{PF}_{6}\right)_{2}(6 \mathrm{~h})$ In a patent application with the same priority date as the above patent, it was shown that the activity of the carboxylate bridged dimer can be further improved by addition of ascorbic acid palmitate [27]. It was also shown that $\left[\mathrm{Mn}^{\mathrm{IV}, \mathrm{IV}}{ }_{2}(\mu-\mathrm{O})_{3}\left(\mathrm{Me}_{3} \mathrm{TACN}\right)_{2}\right]\left(\mathrm{CH}_{3} \mathrm{CO}_{2}\right)_{2}$ is significantly more active towards paint drying than $\left[\mathrm{Mn}^{\mathrm{IV}, \mathrm{IV}}{ }_{2}(\mu-\mathrm{O})_{3}\left(\mathrm{Me}_{3} \mathrm{TACN}\right)_{2}\right]\left(\mathrm{PF}_{6}\right)_{2}[28]$.

Two patents filed by Akzo Nobel claimed the use of mixtures of $\mathrm{Mn}^{\mathrm{II}}$ salts and either molar excess of $\mathrm{Me}_{3} \mathrm{TACN}$ ligand with respect to $\mathrm{Mn}^{\mathrm{II}}$ salt or molar excess of $\mathrm{Mn}^{\mathrm{II}}$ salt with respect to $\mathrm{Me}_{3} \mathrm{TACN}$ ligand in paint or coatings formulations [29,30]. The use of molar excess of ligand allows the paint formulator to reduce the amount of manganese salt in the paint formulation, thereby reducing the color due to Mn(III) species (improved drying/yellowing balance), as shown in the experimental section in this patent application (yellowing $\mathrm{b}^{*}$ value according to CIE-lab color space reduced from eight to four with a similar drying time when decreasing Mn level from $0.04 \mathrm{wt} \%\left({\mathrm{Mn}: \mathrm{Me}_{3} \mathrm{TACN}}_{1}\right.$ 1:1) to $0.0025 \%$ (Mn:Me $\left.{ }_{3} \mathrm{TACN}=1: 5\right)$. Using molar excess of Mn(II) salt increased the hardness values of dried coating. Both paint formulations containing solvent-borne and water-borne formulations are claimed. A more recent patent application claimed the use of mixtures of dinuclear manganese complexes with $\mathrm{Me}_{3} \mathrm{TACN}$, such as $\left[\mathrm{Mn}^{\mathrm{IV}, \mathrm{IV}}{ }_{2}(\mu-\mathrm{O})_{3}\left(\mathrm{Me}_{3} \mathrm{TACN}\right)_{2}\right]\left(\mathrm{PF}_{6}\right)_{2}$, and additional $\mathrm{Me}_{3} \mathrm{TACN}$ ligand in the coating formulation with the alkyd-resin [31]. The examples in this patent showed a relatively poor paint drying activity when using $\left[\mathrm{Mn}^{\mathrm{IV}, \mathrm{IV}}{ }_{2}(\mu-\mathrm{O})_{3}\left(\mathrm{Me}_{3} \mathrm{TACN}\right)_{2}\right]\left(\mathrm{PF}_{6}\right)_{2}$ without extra added $\mathrm{Me}_{3}$ TACN ligand (drying time of $18.5 \mathrm{~h}$ when using this complex at $0.05 \mathrm{wt} \% \mathrm{Mn}$ ), which improved markedly when an additional five molar equivalent of $\mathrm{Me}_{3} \mathrm{TACN}$ ligand was added to the same complex at $0.025 \mathrm{wt} \% \mathrm{Mn}$ (drying time of $7 \mathrm{~h}$ ). In addition, the yellowing was shown to remain within the same range as what was found when tesing $\mathrm{Co}^{\mathrm{II}}(2-\mathrm{EH})_{2}$ as a reference.

Chemsenti filed a patent on alkyd resin formulations with a ligand included that do not contain transition-metal ions [32]. According to this patent, the paint formulator can then upon producing the paint or coating composition add the appropriate amount of manganese or iron salt to allow the formation of the siccative in the formulation. An advantage claimed is that no skinning can occur in the alkyd resin formulation prior the addition of iron or manganese salts, as the free ligand will not react with the alkyd resin and oxygen to initiate autoxidation processes. Preferred ligands are $\mathrm{Me}_{3} \mathrm{TACN}, \mathrm{Me}_{4} \mathrm{DTNE}$, bpy and phen. In the experimental section of this patent application, it was shown that storage stable mixtures of alkyd resin and various ligands can be obtained, which upon addition of various Mn salts give good alkyd-paint drying activity. Another patent filed by Chemsenti claimed the use of Mn complexes with $\mathrm{Me}_{4}$ DTNE or $\mathrm{Me}_{4}$ DTNE mixed with Mn salts for alkyd-paint drying [33]. The experiments showed good paint drying activity when using a manganese salt mixed with the $\mathrm{Me}_{4} \mathrm{DTNE}$ ligand, which is much higher than observed for $\mathrm{Mn}^{\mathrm{II}}(2-\mathrm{EH})_{2}$.

Catexel filed a patent that claimed formulations of $\mathrm{Me}_{3} \mathrm{TACN}$ ligand and $\mathrm{Mn}$ (II) and/or $\mathrm{Mn}$ (III) salts in an alcohol or ketone solvent to be added to alkyd-containing coating formulations [34]. The manganese salts included $\mathrm{Mn}^{\mathrm{II}}(\text { acetate })_{2}, \mathrm{Mn}^{\mathrm{III}}(\text { acetate })_{3}, \mathrm{Mn}^{\mathrm{II}}$ (chloride $)_{2}$ and $\left[\mathrm{Mn}^{\mathrm{III}}(\text { acac })_{3}\right]$. Again, good drying performances were obtained and often similar or better than when doing similar experiments with $\mathrm{Mn}^{\mathrm{II}}(2-\mathrm{EH})_{2}$. A similar patent application covered the use of $\mathrm{Me}_{4} \mathrm{DTNE}$ in the same solvent mixtures [35].

From the rather long list of papers and patents, it is clear that there is considerable interest in the application of manganese complexes with 1,4,7-triazacyclononane based ligands. What is less clear from these publications is the nature of the catalytically active species involved in the alkyd-paint drying. The lower drying activity of the $\left[\mathrm{Mn}^{\mathrm{IV}, \mathrm{IV}}{ }_{2}(\mu-\mathrm{O})_{3}\left(\mathrm{Me}_{3} \mathrm{TACN}\right)_{2}\right]\left(\mathrm{PF}_{6}\right)_{2}$ complex suggests that such species is not involved in the catalysis and merely a precursor of the active species [28].

Although one can most likely conclude, based on the studies $[23,26]$ on the reactivity of $\left[\mathrm{Mn}^{\mathrm{IV}, \mathrm{IV}}{ }_{2}(\mu-\mathrm{O})_{3}\left(\mathrm{Me}_{3} \mathrm{TACN}\right)_{2}\right]\left(\mathrm{PF}_{6}\right)_{2}$ with alkyd paints, that radical based autoxidation chemistry will be operative for the $\mathrm{Mn}-\mathrm{Me}_{3} \mathrm{TACN}$ complexes or mixtures discussed in different patents, further detailed investigations would be needed to elucidate the nature of the catalytically active species 
involved in alkyd paint drying using different sources of Mn-Me 3 TACN and whether different sources of $\mathrm{Mn}-\mathrm{Me}_{3} \mathrm{TACN}$ would lead to the same mechanistic pathways of radical-based alkyd resin curing.

\subsubsection{Other Manganese Based Catalysts}

In a patent application by Akzo Nobel, it was shown that addition of Schiff base ligands to a Mn-soap leads to a reduction of drying time by a factor of three. One of the exemplified ligands used in the paint drying tests, $N, N^{\prime}$-bis(salicylidene)cyclohexylenediamine, is shown in Figure 3 [36]. Without discussing the considerable chemistry and catalysis of Mn Schiff-base complexes published in detail, it should be noted that reactivity of this class of catalysts with ${ }^{t} \mathrm{BuOOH}$ as oxidant with cyclohexene is well known [37].

Manganese porphyrins are active to cure alkyd resins as well, as shown in a recent patent application by Dura Chemicals [38]. The results presented in the patent applications suggest that $\mathrm{Mn}^{\mathrm{III}}\left(5,10,15,20\right.$-tetrakisphenylporphyrin) is much more active than $\mathrm{Co}^{\mathrm{II}}(2-\mathrm{EH})_{2}$ based on metal level. The examples also show that when the Mn-porphyrin drier is added to various paint formulations, the change in the color $\left(\mathrm{L}^{*}, \mathrm{a}^{*}, \mathrm{~b}^{*}\right.$ values) of the paint is similar or less than when compared with $\mathrm{Co}^{\mathrm{II}}(2-\mathrm{EH})_{2}$. As Mn-porphyrins are well known for their intense color, these observations suggest that they have been formulated at low concentrations. This will be especially important if the paint formulator wants to use these catalysts in white or light-colored paints.

In a recent patent application, it was shown that mixtures of various tri-, tetra- and pentadentate 1,4-diazacycloheptane-based ligands (Figure 3) with $\mathrm{Mn}^{\mathrm{II}}(2-\mathrm{EH})_{2}$ or $\mathrm{Mn}^{\mathrm{II}}\left(\mathrm{CH}_{3} \mathrm{CO}_{2}\right)_{2}$ at $0.07 \mathrm{wt} \%$ vs. solid resin showed good drying of an alkyd resin between 2 and $4 \mathrm{~h}$, depending on the ligand used [39]. $\mathrm{Mn}^{\mathrm{II}}(2-\mathrm{EH})_{2}$ without ligand added at the same level did not show alkyd drying activity within $8 \mathrm{~h}$.

In a patent that covers various classes of iron and manganese complexes with polydentate ligands, manganese complexes with a cross-bridged tetraaza macrocyclic ligand (Bcyclam) (Figure 3) are also shown to be active towards paint drying [40]. In a set of experiments $\beta$-carotene was used as a model substrate that was bleached upon reaction with alkoxy or peroxyl radicals. It was shown that a manganese complex with the Bcyclam ligand bleaches $\beta$-carotene in conjunction with methyllinoleate, and that its extent of bleaching within 10 min was about seven times higher than $\mathrm{Co}^{\mathrm{II}}(\mathrm{EH})_{2}$ at the same molar concentration. In addition, on linseed varnish, this Mn-Bcyclam catalyst showed drying activity at five times lower concentration than $\mathrm{Co}^{\mathrm{II}}(\mathrm{EH})_{2}$.

\section{Iron Catalysts}

\subsection{Iron Soaps}

Compared to Co-soap and even Mn-soap, Fe-soap siccatives are not very active for paint drying. They are mainly used in high-temperature curing, such as in stoving enamels [1]. Furthermore, iron(III) carboxylate compounds are markedly colored, which together with relatively high levels needed, make them unsuitable for many coating applications $[3,41]$.

Studies on ethyllinoleate revealed that $\mathrm{Fe}^{\mathrm{II}}(2-\mathrm{EH})_{2}$ did not react readily with the substrate, as monitored by FTIR at $3010 \mathrm{~cm}^{-1}$ (symmetric cis-C=C-H streching), showing a lag-time of

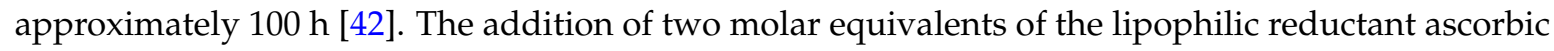
acid palmitate led to an immediate decrease in the peak intensity of the cis- $\mathrm{C}=\mathrm{C}$ vibration. Increasing the amount of ascorbic acid further led to a reduction of the reactivity with ethyllinoleate. In addition, experiments using NMR, size exclusion chromatography and peroxide determinations supported the conclusion that the addition of ascorbic acid leads to an increase in reactivity, including formation of oligomers. It was suggested that trinuclear Fe species are formed that can lead to reactivity with the substrate only if one the iron centers is reduced to $\mathrm{Fe}^{\mathrm{II}}$ [42,43]. In addition, coating and paint drying tests were conducted using an Fe-soap/ascorbic acid mixture [44,45]. Similar or even improved drying times were observed as compared to the standard $\mathrm{Co}^{\mathrm{II}}(2-\mathrm{EH})_{2}$ drier. An improvement was noted when one to four molar equivalents of imidazole ligand was added, presumably because of binding to 
the active iron catalyst. Interestingly, in some of the experiments where ascorbic acid palmitate was added to the iron soap, a reduced tendency of skinning was observed. Although these findings are interesting, the need to add co-reductants into the paint formulation may make the use of ascorbic acid as an activator for the iron catalyst less desirable.

\subsection{Iron Complexes}

\subsubsection{Iron Bispidon Catalysts}

Recently, a very active iron catalyst based on a pentadentate nitrogen donor has been described $[40,41]$. The structure of the catalyst is [(bispidon) $\left.\mathrm{Fe}{ }^{\mathrm{II}} \mathrm{Cl}\right] \mathrm{Cl}$, where bispidon is the abbreviation of dimethyl 3-methyl-9-oxo-2,4-di(pyridin-2-yl)-7-(pyridin-2-ylmethyl)-3,7-diazabicyclo nonane-1,5-dicarboxylate) (Figure 4). This catalyst was developed originally by Unilever for detergent cleaning applications and showed a high activity on food-oil stains in the absence of hydrogen peroxide bleaches [46,47]. Food stains typically contain unsaturated oils such as sunflower or olive oil, and it was found that during laundry bleaching similar mechanisms are operative as discussed above for paint drying. Hydroperoxide intermediates are formed during the ageing or cooking process, which, after activation by the iron catalyst, generate alkoxy and/or alkylperoxy radicals, leading in turn to bleaching of the colored chromophores (often lycopene based) [46-50].

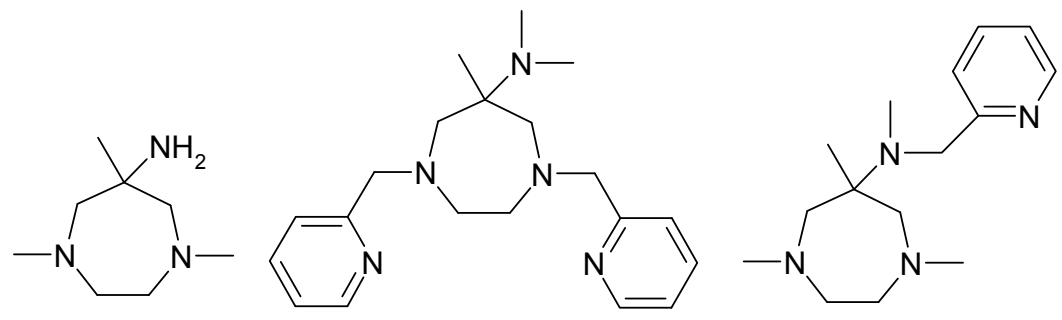

Examples of 1,4-diazacycloheptane ligands<smiles>COC(=O)C12CN(Cc3ccccn3)CC1(C(=O)OC)C(O)(C(=O)O)C(c1ccccn1)N(C)C2c1ccccn1</smiles>
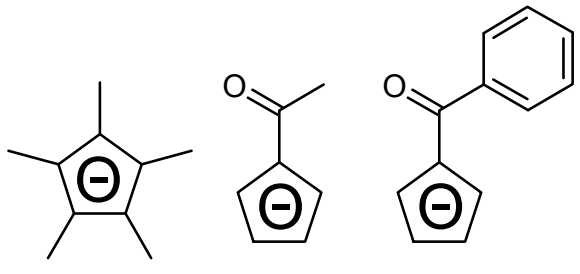

Examples of ferrocene ligands<smiles>CC(c1ccccn1)(c1ccccn1)N(Cc1ccccn1)Cc1ccccn1</smiles>

bispidon

Figure 4. Ligands exhiting paint drying activity as Fe-ligand complexes. Examples of 1,4-diazacycloheptane based ligands depicted: 6-amino-1,4,6-trimethyl-1,4-diazacycloheptane, 6-dimethylamino-1,4-bis(pyridine-2-ylmethyl)-6-methyl-1,4-diazacycloheptane, 1,4,6-trimethyl-6\{N(pyridin-2-ylmethyl)- $N$-methylamino\}-1,4-diazacycloheptane, bispidon = dimethyl 3-methyl-9-oxo-2, 4-di(pyridin-2-yl)-7-(pyridin-2-ylmethyl)-3,7-diazabicyclo[3.3.1]nonane-1,5-dicarboxylate, examples of ferrocene ligands depicted: ferrocene, acylferrocene, benzeneacylferrocene, and MeN4Py = N,N-bis(pyridin-2-ylmethyl)-1,1-bis(pyridine-2-yl)-1-amino-ethane.

It was shown that, on a medium-oil SB alkyd resin, the drying time of the iron bispidon catalyst at $0.00065 \mathrm{wt} \%$ Fe was similar to that of a standard cobalt-zirconium siccative at about $0.08 \mathrm{wt} \%$ of cobalt metal [41]. Interestingly, increasing the amount of iron catalyst led to a slowdown of the drying process, which has been assigned to too fast drying on the surface of the paint layer, thereby preventing dioxygen diffusion in the inner layer that is needed to obtain polymerizations. In water-borne alkyd 
paint, the dosage of the catalyst could be as low as $0.0002 \mathrm{wt} \% \mathrm{Fe}$. A benefit noted was that at lower temperatures the relative performance of the iron bispidon catalyst remained more constant than what was seen with the cobalt soap drier, especially in water-born alkyd paints. Furthermore, the yellowing due to use of this catalyst was often lower than seen with the cobalt soap drier, due to the low dosage used. In addition, experiments were done to test for skinning behavior upon storage in the paint can. It was observed that the standard antiskinning agent MEKO, suitable for cobalt based siccatives, was not very effective with this catalyst, which led to the suggestion that steric constraints due to the bulky ligand prevent binding of MEKO to the iron center. Approaches like adding other anti-oxidants [41], dissolving the catalyst in water [51], and developing paint formulations with granules containing the catalyst that release the siccative upon applying to the surface [52] have been investigated as alternatives to the MEKO antiskinning agent.

Model studies were conducted using Raman spectroscopy on ethyllineolate upon addition of [(bispidon) $\left.\mathrm{Fe}{ }^{\mathrm{II}} \mathrm{Cl}\right] \mathrm{Cl}$ [41]. Similarly to some other catalysts discussed above, the double allylic $-\mathrm{CH}_{2}-$ group and non-conjugated cis carbon-carbon double bonds disappear over time, whilst the formation of conjugated carbon-carbon double bonds was observed. With FTIR the disappearance of cis $\mathrm{C}=\mathrm{C}-\mathrm{H}$ symmetric stretching band and the formation of conjugated trans $\mathrm{C}=\mathrm{C}-\mathrm{H}$, isolated trans $\mathrm{C}=\mathrm{C}-\mathrm{H}, \mathrm{ROH}$, $\mathrm{ROOH}$ and carbonyl groups was observed. These changes are in agreement with other studies with other siccatives and point to formation of alkylperoxides, formation of conjugated double bonds and intermolecular cross-linking (vide supra). Interestingly, comparable rates of changes in the Raman and IR spectra of ethyllinoleate were observed using $\mathrm{Co}^{\mathrm{II}}(2-\mathrm{EH})_{2}$ and [(bispidon) $\left.\mathrm{Fe}^{\mathrm{II}} \mathrm{Cl}\right] \mathrm{Cl}$ as catalyst when tested at similar metal level. This is in contrast to what has been observed when testing these compounds for alkyd-paint drying (vide supra), where [(bispidon) $\left.\mathrm{Fe}{ }^{\mathrm{II}} \mathrm{Cl}\right] \mathrm{Cl}$ showed activity at lower levels than $\mathrm{Co}^{\mathrm{II}}(2-\mathrm{EH})_{2}$. Although the reasons for these differences are not well understood, it is clear that one has to be careful in making predictions on the actual performance of a paint drying catalyst in the (more complicated) alkyd based paints, based on the performance with model substrate conversions only.

In a study by Pirš et al., $\mathrm{Co}^{\mathrm{II}}(2-\mathrm{EH})_{2}$ as a drier was compared with [(bispidon)Fe $\left.{ }^{\mathrm{II}} \mathrm{Cl}\right] \mathrm{Cl}$ in high-solid (HS) alkyd paints [53]. Based on the drying experiments, it was suggested that $\mathrm{Co}^{\mathrm{II}}(2-\mathrm{EH})_{2}$ starts to dry to a coating layer on the surface film soon after the solvent has evaporated, whilst the iron drier showed a more uniform drying behavior throughout the entire coating/thickness. The cis $\mathrm{C}=\mathrm{C}-\mathrm{H}$ symmetric stretching band at $3007 \mathrm{~cm}^{-1}$ in HS alkyd coatings was monitored to rank the activity of the $\mathrm{Co}^{\mathrm{II}}(2-\mathrm{EH})_{2}$ drier $v s$. [(bispidon) $\left.\mathrm{Fe}^{\mathrm{II}} \mathrm{Cl}\right] \mathrm{Cl}$. It was shown that the cobalt drier exhibited a shorter induction period than measured for [(bispidon) $\left.\mathrm{Fe}^{\mathrm{II}} \mathrm{Cl}\right] \mathrm{Cl}$ as siccative and that also the rate of depletion of the $\mathrm{C}=\mathrm{C}-\mathrm{H}$ band was faster for the cobalt drier. However, it should be noted that the metal content (relative to the resin) in these experiments was $0.1 \mathrm{wt} \%$ for the $\mathrm{Co}^{\mathrm{II}}(2-\mathrm{EH})_{2}$ drier and $0.0007 \mathrm{wt} \%$ for [(bispidon) $\left.\mathrm{Fe}^{\mathrm{II}} \mathrm{Cl}\right] \mathrm{Cl}$ drier. Elasto-viscosicity measurements also indicated that the $\mathrm{Co}^{\mathrm{II}}(2-\mathrm{EH})_{2}$ started to cure at the outer layer leading to yield a stronger top structure, whilst the [(bispidon) $\left.\mathrm{Fe}^{\mathrm{II}} \mathrm{Cl}\right] \mathrm{Cl}$ catalyst induced radical curing more throughout the film. This has also been corroborated by hardness tests. These indicated that harder films were being formed when using $\mathrm{Co}^{\mathrm{II}}(2-\mathrm{EH})_{2}$. Electrochemical impedance spectroscopy was conducted to measure the diffusion of ions through the coating film, which provided information on the extent of crosslinking of the polymer structure (a higher diffusion value implies lower crosslinking of the polymer). Indeed, the cobalt soap showed significantly higher diffusion values than the [(bispidon) $\left.\mathrm{Fe}^{\mathrm{II}} \mathrm{Cl}\right] \mathrm{Cl}$ drier.

In another paper by Pirš et al. [54], the effect of strontium soaps on the curing behavior of $\mathrm{Co}^{\mathrm{II}}(2-\mathrm{EH})_{2}$ and [(bispidon) $\left.\mathrm{Fe}^{\mathrm{II}} \mathrm{Cl}\right] \mathrm{Cl}$ was studied. The cobalt level in the formulation was between 0.08 and $0.14 \mathrm{wt} \%$ when using $\mathrm{Co}^{\mathrm{II}}(2-\mathrm{EH})_{2}$ and the iron level was between 0.00056 and $0.00098 \mathrm{wt} \%$ when using [(bispidon) $\left.\mathrm{Fe}^{\mathrm{II}} \mathrm{Cl}\right] \mathrm{Cl}$. First, it was shown through $\mathrm{IR}$, by monitoring the vibration at $3007 \mathrm{~cm}^{-1}$ (cis $\mathrm{C}=\mathrm{C}-\mathrm{H}$ symmetric stretching), that the lag-phase was shortened when adding $\mathrm{Sr}(\mathrm{EH})_{2}$. The rate of depletion of the $3007 \mathrm{~cm}^{-1}$ band was higher for $\mathrm{Co}^{\mathrm{II}}(2-\mathrm{EH})_{2}$ than for [(bispidon) $\left.\mathrm{Fe}^{\mathrm{II}} \mathrm{Cl}\right] \mathrm{Cl}$, although again the dosing of the cobalt soap siccative was higher than [(bispidon) $\left.\mathrm{Fe}^{\mathrm{II}} \mathrm{Cl}\right] \mathrm{Cl}$. The effect 
of Sr soap on the drying time of HS alkyd resins and hardness development was more pronounced with cobalt than with [(bispidon) $\left.\mathrm{Fe}^{\mathrm{II}} \mathrm{Cl}\right] \mathrm{Cl}$. Only at the highest level of $\mathrm{Sr}$ tested was the rate of curing and hardness with [(bispidon) $\left.\mathrm{Fe}^{\mathrm{II}} \mathrm{Cl}\right] \mathrm{Cl}$ clearly higher. This led to the conclusion that, under these latter conditions, first skin layer drying/polymerization took place, more reminiscent to what is normally seen with $\mathrm{Co}^{\mathrm{II}}(2-\mathrm{EH})_{2}$. The electrochemical impedance measurements showed similar results, supporting that [(bispidon) $\left.\mathrm{Fe}^{\mathrm{II}} \mathrm{Cl}\right] \mathrm{Cl}$ exhibited a more uniform polymerization behavior in the film than $\mathrm{Co}^{\mathrm{II}}(2-\mathrm{EH})_{2}$, which showed high activity on the outer layer. The latter has been observed as well by Erich and co-workers in their studies by using various techniques, including high spatial resolution NMR profiling [25].

\subsubsection{Iron Ferrocene Catalysts}

The reactivity of a series of methyl-substituted ferrocene complexes (Figure 4) on ethyllinoleate was studied by FTIR by following the disappearance of the band at $3006 \mathrm{~cm}^{-1}$ [55]. The reactivity for all complexes were quite similar to that of $\mathrm{Co}^{\mathrm{II}}(2-\mathrm{EH})_{2}$, except for the absence of a lag-time as observed for the cobalt drier. Interestingly, the complex with the highest number of methyl groups showed the highest reactivity and this complex was about $20 \%$ faster than the cobalt drier.

In a follow-up study, mixtures of $\mathrm{Co}^{\mathrm{II}}(2-\mathrm{EH})_{2}$ and methylated ferrocene complexes were tested on autoxdation of ethyllinoleate, as followed by FTIR, and on a commercial alkyd resin [56]. It was shown that the mixtures of the ferrocene and $\mathrm{Co}^{\mathrm{II}}(2-\mathrm{EH})_{2}$ catalysts did not exhibit a lag-phase in the ethyllinoleate oxidation. The methylated ferrocence catalysts with electron withdrawing groups showed the best synergistic effects with $\mathrm{Co}^{\mathrm{II}}(2-\mathrm{EH})_{2}$. When testing hardness development on the alkyd resin, the mixtures of the ferrocene derivatives and the cobalt soap were after one month clearly better than the cobalt soap by itself. After two months drying, the hardness values of the alkyd resin film were quite similar for the best cobalt/ferrocene mixtures and cobalt soap.

Acyl-substituted ferrocenes, such as acetyl- and benzoyl-substituted ferrocene (Figure 4), were the subject of a follow-up study by the same group [57]. It was shown that the most active ones tested in solvent-borne alkyd resin were more efficient than $\mathrm{Co}^{\mathrm{II}}(2-\mathrm{EH})_{2}$ (all at $0.1 \mathrm{wt} \%$ of metal vs. solid dry matter). In addition, a faster improvement of hardness development than the reference cobalt drier was observed. The parent compound, ferrocene, exhibited no alkyd paint drying activity. Alkyd autoxidation reactions were monitored using FTIR as well [57]. The initial rate of the depletion of the double allylic $\mathrm{CH}_{2}$ group was initially higher for some of the acetylferrocene derivatives than for $\mathrm{Co}^{\mathrm{II}}(2-\mathrm{EH})_{2}$; however, after 5-10 $\mathrm{min}$, the rate of depletion of the allylic $\mathrm{CH}_{2}$ group was higher for $\mathrm{Co}^{\mathrm{II}}(2-\mathrm{EH})_{2}$. Spin-trap experiments have indicated that the ferrocene catalysts form mainly alkoxy radicals, whilst with $\mathrm{Co}^{\mathrm{II}}(2-\mathrm{EH})_{2}$ both alkoxy and peroxyl radicals were trapped. All acetylferrocene catalysts were surpassed by $\mathrm{Co}^{\mathrm{II}}(2-\mathrm{EH})_{2}$ when tested for $\mathrm{OH}$ formation (originating from alkylperoxides and $\mathrm{OH}$-containing alkyd reaction products). Further experiments were conducted by testing mixtures of $\mathrm{Co}^{\mathrm{II}}(2-\mathrm{EH})_{2}$ with commercially available acetylferrocene derivatives, which showed that considerable synergistic effects were obtained. The levels of the $\mathrm{Co}^{\mathrm{II}}(2-\mathrm{EH})_{2}$ and acylferrocene catalysts used were each $0.025 \mathrm{wt} \%$ of the metal with respect to resin [57].

\subsubsection{Other Iron-Based Catalysts}

Besides the iron alkyd paint drying catalysts that were presented in some detail above, another iron catalyst with a pentadentate nitrogen donor ligand was exemplified in a patent by Unilever [40]: the iron complex with the pentadentate ligand MeN4Py (N,N-bis(pyridin-2-yl-methyl-1,1-bis(pyridin-2-yl)-1-aminoethane) (Figure 4). This compound has previously been identified by Unilever as potential bleaching catalyst [46]. The data in the patent showed a similar linseed oil drying activity for $\left[\mathrm{Fe}^{\mathrm{II}}(\mathrm{MeN} 4 \mathrm{Py}) \mathrm{Cl}\right] \mathrm{Cl}$ as what has been observed for [(bispidon) $\left.\mathrm{Fe}^{\mathrm{II}} \mathrm{Cl}\right] \mathrm{Cl}$. In addition, it was shown that $\left[\mathrm{Fe}^{\mathrm{II}}(\mathrm{MeN} 4 \mathrm{Py}) \mathrm{Cl}\right] \mathrm{Cl}$ bleached $\beta$-carotene in conjunction with methyllinoleate, and that its extent of bleaching within $10 \mathrm{~min}$ was about six times higher than $\mathrm{Co}^{\mathrm{II}}(\mathrm{EH})_{2}$ at the same molar concentration. 
The same class of 1,4-diazacycloheptane-based ligands (Figure 4) as discussed above in combination with manganese were also tested in combination with iron naphthenate salt for alkyd-paint drying [39]. In addition, faster drying was observed here than when testing the iron soap without these ligands; a drying time between $2.5 \mathrm{~h}$ and $6.5 \mathrm{~h}$, depending on the ligand used, was found, whilst the iron soap without ligand did not show any tendency of alkyd resin drying within $8 \mathrm{~h}$.

\section{Conclusions}

In the last two decades, various manganese and iron compounds have been reported as alternatives to cobalt soap siccatives. In some cases, the information available on the activity and properties of these siccatives is quite extensive, whilst, for various manganese and iron catalysts, one has to rely on (often a limited number of) examples given in patents. The patents show often only the paint drying activity in certain alkyd-resin formulations without further information on the activity in other types of paint (e.g., water-borne vs. solvent-borne formulations).

Besides the paint drying activity, other parameters that should be considered before choosing an alternative paint drying catalyst include the propensity of skinning activity in paint formulations, the color in the formulation due to the color of the siccative (or the species formed upon mixing, storing or applying the paint), the effect of pigments or fillers on the paint drying catalyst, etc. If a paint formulator wants to develop an alternative to cobalt soap, one has to measure such properties as well, besides the drying times in the appropriate paint formulations. Furthermore, it should be noted that, in many cases, paint formulations are used that have been optimized previously for a good performance with cobalt soaps according to criteria listed above. It is a priori not certain whether the paint formulations will need to be adapted for the use of an alternative siccative. For example, MEKO is an efficient anti-skinning agent for $\mathrm{Co}^{\mathrm{II}}(2-\mathrm{EH})_{2}$ due to the reversible binding to the redox-active cobalt ion, whilst it may not be binding well to other paint drying catalysts, for example as found for [(bispidon)Fe $\left.{ }^{\mathrm{II}} \mathrm{Cl}\right] \mathrm{Cl}$. Further adaption, e.g., using other anti-skinning agents may be more suitable in such case.

Besides the paint drying tests carried out with the different catalysts discussed above, some of them have also been the subject of more detailed mechanistic investigations. Ethyllinoleate has especially been used as a model compound for alkyd resins with FTIR and Raman spectroscopy used regularly to monitor reactivity. Although clear differences in lag-phase and rates were observed, generally similar reactions were monitored: conversion of non-conjugated alkene groups $\left(-\mathrm{C}=\mathrm{C}-\mathrm{CH}_{2}-\mathrm{C}=\mathrm{C}-\right)$ to conjugated alkene groups $(-\mathrm{C}=\mathrm{C}-\mathrm{C}=\mathrm{C}-$ ) and formation of $\mathrm{ROH}, \mathrm{ROOH}$ and aldehydes. In addition, in some cases the formation of volatile aldehydes (e.g., hexanal, heptanal) was studied using GC, albeit with different rates for different siccatives. The studies performed to date suggest that, during alkyd resin polymerization reactions, radical based curing takes place, although details might be quite different for each catalyst. For example, some may be active by accelerating the initiation reactions (i.e., $\mathrm{H}^{\bullet}$ abstraction of the allylic $\mathrm{CH}_{2}$ group), whilst others may be more effective in activating the $\mathrm{ROOH}$ when present in the alkyd resins.

It is clear though, that quite a few alternatives to the cobalt siccatives have been developed and others may be published in the future. It should therefore be feasible for paint and ink suppliers and producers to develop one or more of the aforementioned catalysts in commercial applications of alkyd-containing paints or inks as viable alternatives to cobalt based siccatives.

Acknowledgments: This research was funded by Catexel Ltd. (Leiden, The Netherlands).

Author Contributions: The content of this manuscript was prepared through equal contribution of the authors Ronald Hage, Johannes W. de Boer and Karin Maaijen.

Conflicts of Interest: The authors declare no conflict of interest. 


\section{Abbreviations}

The following abbreviations are used in this manuscript:

\begin{tabular}{|c|c|}
\hline acac & acetylacetonate \\
\hline bispidon & $\begin{array}{l}\text { dimethyl 3-methyl-9-oxo-2,4-di(pyridin-2-yl)-7-(pyridin-2-ylmethyl)-3, } \\
\text { 7-diazabicyclo[3.3.1]nonane-1,5-dicarboxylate }\end{array}$ \\
\hline bpy & $2,2^{\prime}$-bipyridine \\
\hline 2-EH & 2-ethylhexanoate \\
\hline FTIR & Fourier Transform Infrared Spectroscopy \\
\hline GC & gas chromatography \\
\hline HMTT & $N, N, N^{\prime}, N^{\prime \prime}, N^{\prime \prime \prime}, N^{\prime \prime \prime}$-hexamethyltriethylenetetraamine \\
\hline HS & high solid \\
\hline $\mathrm{Me}_{4} \mathrm{DTNE}$ & 1,2-bis(4,7-dimethyl-1,4,7-triazacyclononan-1-yl)-ethane \\
\hline MeN4Py & $N, N$-bis(pyridin-2-yl-methyl-1,1-bis(pyridin-2-yl)-1-aminoethane \\
\hline $\mathrm{Me}_{3} \mathrm{TACN}$ & 1,4,7-trimethyl-1,4,7-triazacyclononane \\
\hline MEKO & methylethylketoxime \\
\hline MS & mass spectrometry \\
\hline phen & 1,10-phenanthroline \\
\hline $\begin{array}{l}\mathrm{REACH} \\
\mathrm{SB}\end{array}$ & $\begin{array}{l}\text { Registration, Evaluation, Authorisation and Restriction of Chemicals } \\
\text { solvent-borne }\end{array}$ \\
\hline VOC & volatile organic compounds \\
\hline WB & water-borne \\
\hline
\end{tabular}

\section{References}

1. Soucek, M.D.; Khattab, T.; Wu, J. Review of autoxidation and driers. Prog. Org. Coat. 2012, 73, 435-454. [CrossRef]

2. Hofland, A. Alkyd resins: From down and out to alive and kicking. Prog. Org. Coat. 2012, 73, 274-282. [CrossRef]

3. Bieleman, J.H. Driers. Chimia 2002, 56, 184-190. [CrossRef]

4. Van Gorkum, R.; Bouwman, E. The oxidative drying of alkyd paint catalysed by metal complexes. Coord. Chem. Rev. 2005, 249, 1709-1728. [CrossRef]

5. Greimel, K.J.; Perz, V.; Koren, K.; Feola, R.; Temel, A.; Sohar, C.; Herrero Acero, E.; Klimant, I.; Guebitz, G.M. Banning toxic heavy-metal catalysts from paints: Enzymatic cross-linking of alkyd resins. Green Chem. 2013, 15, 381-388. [CrossRef]

6. Preininger, O.; Vinklárek, J.; Honzíček, J.; Mikysek, T.; Erben, M. A promising drying activity of environmentally friendly oxovanadium(IV) complexes in air-drying paints. Prog. Org. Coat. 2015, 88, 191-198. [CrossRef]

7. Manzano, E.; Navas, N.; Checa-Moreno, R.L.; Rodriguez-Simón, L.; Capitán-Vallvey, L.F. Preliminary study of UV ageing process of proteinaceuous paint binder by FT-IR and principal component analysis. Talanta 2009, 77, 1724-1731. [CrossRef] [PubMed]

8. Jensen, M.P.; Payeras, A.M.I.; Fiedler, A.T.; Costas, M.; Kaizer, J.; Stubna, A.; Muenck, E.; Que, L., Jr. Kinetic analysis of the conversion of nonheme (alkylperoxo)iron(III) species to iron(IV) complexes. Inorg. Chem. 2007, 46, 2398-2408. [CrossRef] [PubMed]

9. Kaizer, J.; Costas, M.; Que, L., Jr. A dramatic push effect on the homolysis of $\mathrm{Fe}^{\mathrm{III}}(\mathrm{OOR})$ intermediates to form non-heme $\mathrm{Fe}^{\mathrm{IV}}=\mathrm{O}$ complexes. Angew. Chem. Int. 2003, 42, 3671-3673. [CrossRef] [PubMed]

10. Coggins, M.K.; Martin-Diaconescu, V.; DeBeer, S.; Kovacs, J.A. Correlation between structural, spectroscopic, and reactivity properties within a series of structurally analogous manganese(III)-alkylperoxo complexes. J. Am. Chem. Soc. 2013, 135, 4260-4272. [CrossRef] [PubMed]

11. Chavez, F.A.; Rowland, J.M.; Olmstead, M.M.; Mascharak, P.K. Synthesis, structures and reactivities of cobalt(III)-alkylperoxo complexes and their role in stoichiometric and catalytic oxidation of hydrocarbons. J. Am. Chem. Soc. 1998, 120, 9015-9027. [CrossRef] 
12. Clauwaert, E. Cobalt-Based Catalytic Dryer for Polymer Coatings. WO2010076031, 8 July 2010.

13. Tanase, S.; Hierso, J.-C.; Bouwman, E.; Reedijk, J.; ter Borg, J.; Bieleman, J.H.; Schut, A. New insights in anti-skinning effect of methyl ethyl ketoxime in alkyd paints. New J. Chem. 2003, 27, 854-959. [CrossRef]

14. Oyman, Z.O.; Ming, W.; van der Linde, R. Oxidation of model compound emulsions for alkyd paints under the influence of cobalt drier. Prog. Org. Coat. 2003, 48, 80-91. [CrossRef]

15. Muizebelt, W.J.; Hubert, J.C.; Nielen, M.W.F.; Klaasen, R.P.; Zabel, K.H. Crosslink mechanisms of high-solid alkyd resins in the presence of reactive diluents. Prog. Org. Coat. 2000, 40, 121-130. [CrossRef]

16. Oyman, Z.O.; Ming, W.; van der Linde, R. Oxidation of drying oils containing non-conjugated and conjugated double bonds catalyzed by a cobalt catalyst. Prog. Org. Coat. 2005, 54, 198-204. [CrossRef]

17. Rondas, F. Manganese-Based Catalytic Dryer for Polymer Coatings. WO2012000934, 5 January 2012.

18. Warzeska, S.T.; Zonneveld, M.; van Gorkum, R.; Muizebelt, W.J.; Bouwman, E.; Reedijk, J. The influence of bipyridine on the drying of alkyd paints. A model study. Prog. Org. Coat. 2002, 44, 243-248. [CrossRef]

19. Lima, G.E.S.; Nunes, E.V.; Dantes, R.C.; Meneghetti, M.R.; Meneghetti, S.M.P. Systematic investigation of the oxidative polymerization of linseed oil catalysed by $\mathrm{Co}(\mathrm{II}), \mathrm{Mn}(\mathrm{II})$, and $\mathrm{Fe}(\mathrm{II})$ complexes with chelating nitrogen ligands. Eur. J. Lipid Sci. Technol. 2015, 117, 229-234. [CrossRef]

20. Van Gorkum, R.; Bouwman, E. Fast Autoxidation of ethyl linoleate catalyzed by $\left[\mathrm{Mn}(\mathrm{acac})_{3}\right]$ and bipyridine: A possible drying catalyst for alkyd paints. Inorg. Chem. 2004, 43, 2456-2458. [CrossRef] [PubMed]

21. Oyman, Z.O.; Ming, W.; van der Linde, R.; Gorkum, R.; Bouwman, E. Effect of $\left[\mathrm{Mn}(\mathrm{acac})_{3}\right]$ and its combination with 2,2'-bipyridine on the autoxidation and oligomerisation of ethyl linoleate. Polymer 2005, 46, 1731-1738. [CrossRef]

22. Van Gorkum, R.; Bouwman, E.; Reedijk, J. Drier for Alkyd Based Coating. EP1382648A, 21 January 2004.

23. Oyman, Z.O.; Ming, W.; Micciche, F.; Oostveen, E.; van Haveren, J.; van der Linde, R. A promising environmentally friendly manganese-based catalyst for alkyd emulsion coatings. Polymer 2004, 45, 7431-7436. [CrossRef]

24. Oyman, Z.O.; Ming, W.; van der Linde, R.; ter Borg, J.; Schut, A.; Bieleman, J.H. Oxidative drying of alkyd paints catalysed by a dinuclear manganese complex (MnMeTACN). Surf. Coat. Int. B Coat. Trans. 2005, 88, 269-275. [CrossRef]

25. Gezici-Koç, Ö.; Thomas, C.A.A.M.; Michel, M.E.B.; Erich, S.J.F.; Huinink, H.P.; Flapper, J.; Duivenvoorde, F.L.; van der Ven, L.G.J.; Adan, O.C.G. In-depth study of drying solvent-borne alkyd coatings in presence of Mnand Fe-based catalysts as cobalt alternatives. Mater. Today Commun. 2016, 7, 22-31. [CrossRef]

26. Oyman, Z.O.; Ming, W.; van der Linde, R. Catalytic activity of a dinuclear manganese complex (MnMeTACN) on the oxidation of ethyllinoleate. Appl. Catal. A Gen. 2007, 316, 191-196. [CrossRef]

27. Jansen, J.; Kleuskens, E.C.; van Summeren, R.; Alsters, P.L. Manganese Complex Drier for Coating Compositions. EP2534215B, 18 August 2011.

28. Jansen, J.; Bergman, F.A.C.; Kleuskens, E.C.; Hage, R. Manganese Salt Complex as Drier for Coating Compositions. WO2011098584, 18 August 2011.

29. Meijer, M.D.; van Weelde, E.; van Dijk, J.T.M.; Flapper, J. Drier for Auto-Oxidisable Coating Compositions. WO2013092441, 27 July 2013.

30. Meijer, M.D.; van Weelde, E.; van Dijk, J.T.M.; Flapper, J. Drier for Auto-Oxidisable Coating Compositions. WO2013092442, 27 July 2013.

31. Meijer, M.D.; Flapper, J. Drier for Auto-Oxidisable COATING compositions. WO2014095670, 26 June 2014.

32. Hage, R.; de Boer, J.W.; Maaijen, K. Drier for Alkyd-Based Coating. WO2014122433, 14 August 2014.

33. Hage, R.; de Boer, J.W.; Maaijen, K. Oxidatively Curable Coating Composition. WO2014122432A, 14 August 2014.

34. De Boer, J.W.; Maaijen, K.; Hage, R. Composition. WO2015114349A, 6 August 2015.

35. De Boer, J.W.; Maaijen, K.; Hage, R. Composition. WO2015114352A, 6 August 2015.

36. Boomgaard, R.E.; Schier, H.; Kirchner, E.J.J.; Klaasen, R.P.; Hartl, F.; van der Leeuw, R.P.C.; Bakkeren, F.J.A.D. Oxidatively Drying Coating Composition. WO2003029371, 10 April 2003.

37. Srinivasan, K.; Perrier, S.; Kochi, J.K. Dual pathways for manganese catalysis of olefin oxidation with alkyl hydroperoxides. J. Mol. Catal. 1986, 36, 297-317. [CrossRef]

38. Santhanam, R. Additives for Curable Liquid Compositions. WO2012092034, 5 July 2012.

39. Hage, R.; de Boer, J.W.; Maaijen, K. Oxidatively Curable Coating Composition. WO2014122434A, 14 August 2014. 
40. Hage, R.; Wesenhagen, P.V. Liquid Hardening. WO2008003652, 10 January 2008.

41. De Boer, J.W.; Wesenhagen, P.V.; Wenker, E.C.M.; Maaijen, K.; Gol, F.; Gibbs, H.; Hage, R. The quest for cobalt-free alkyd paint driers. Eur. J. Inorg. Chem. 2013, 3581-3591. [CrossRef]

42. Miccichè, F.; van Haveren, J.; Oostveen, E.; Ming, W.; van der Linde, R. Oxidation and oligomerization of ethyl linoleate under influence of the combination of ascorbic acid 6 palmitate/iron-2-ethylhexanoate. Appl. Catal. A Gen. 2006, 297, 174-181. [CrossRef]

43. Miccichè, F.; Long, G.J.; Shahin, A.M.; Grandjean, F.; Ming, W.; van Haveren, J.; van der Linde, R. The combination of ascorbic acid 6-palmitate and $\left[\mathrm{Fe}_{3}{ }^{\mathrm{III}}\left(\mu_{3}-\mathrm{O}\right)\right]^{7+}$ as a catalyst for the oxidation of unsaturated lipids. Inorg. Chim. Acta 2007, 360, 535-545. [CrossRef]

44. Van Haveren, J.; Oostveen, E.A.; Miccichè, F.; Noordover, B.A.J.; Koning, C.E.; van Benthem, R.A.T.M.; Frissen, A.E.; Weijnen, J.G.J. Resins and additives for powder coatings and alkyd paints, based on renewable sources. J. Coat. Technol. Res. 2007, 4, 177-186. [CrossRef]

45. Micciche, F. The Combination of Ascorbic Acid Derivatives/Iron Salts as Catalyst for the Oxidative Drying of Alkyd Paints: A Biomimetic Approach. Ph.D. Thesis, Technischie Universiteit Eindhoven, Eindhoven, The Netherlands, 2005.

46. Hage, R.; Lienke, A. Applications of transition-metal catalysts to textile and wood-pulp bleaching. Angew. Chem. Int. Ed. 2006, 45, 206-222. [CrossRef] [PubMed]

47. Hage, R.; de Boer, J.W.; Gaulard, F.; Maaijen, K. Manganese and iron bleaching and oxidation catalysts. Adv. Inorg. Chem. 2013, 65, 85-116.

48. Appel, R.; Hage, R.; van der Hoeven, P.C.; Lienke, J.; Smith, R.G. Enhancement of Air Bleaching Catalysts. EP1368450, 27 June 2002.

49. Appel, R.; Batchelor, S.N.; Grabijn, L.G.; Hage, R.; Jones, S.; Parry, M. Bleaching Composition. WO2005118764, 15 December 2005.

50. Appel, R.; Hage, R.; Lienke, J. Device Suitable for Analysing Edible Oil Quality. EP1326074, 9 July 2003.

51. Hage, R.; Gol, F.; Gibbs, H.W.; Maaijen, K. Antiskinning Compositions. WO2012093250, 12 July 2012.

52. Gibbs, H.W.; Gol, F.; Vrhunec, A.; Stefanec, D.; Pulsar, J. Encapsulated Catalysts. WO2015011430, 29 January 2015.

53. Pirš, B.; Bogdan, Z.; Skale, S.; Zabret, J.; Godnjavec, J.; Venturini, P. Iron as an alternative drier for high-solid alkyd coatings. J. Coat. Technol. Res. 2015, 12, 965-974. [CrossRef]

54. Pirš, B.; Bogdan, Z.; Skale, S.; Zabret, J.; Godnjavec, J.; Berce, P.; Venturini, P. The influence of Co/Sr and Fe/Sr driers on film formation of high-solid alkyd coatings. Acta Chim. Slov. 2015, 62, 52-59. [CrossRef] [PubMed]

55. Kalenda, P.; Holeček, J.; Veselý, D.; Erben, M. Influence of methyl groups on ferrocene on rate of drying of oxidizable paints by using model compounds. Prog. Org. Coat. 2006, 56, 111-113. [CrossRef]

56. Stava, V.; Erben, M.; Vesely, D.; Kalenda, P. Properties of metallocene complexes during the oxidative crosslinking of air drying coatings. J. Phys. Chem. Solids 2007, 68, 799-802. [CrossRef]

57. Erben, M.; Veselý, D.; Vinklárek, J.; Honzíček, J. Acyl-substituted ferrocenes as driers for solvent-borne alkyd paints. J. Mol. Catal. A Chem. 2012, 353-354, 13-21. [CrossRef]

(C) 2016 by the authors; licensee MDPI, Basel, Switzerland. This article is an open access article distributed under the terms and conditions of the Creative Commons Attribution (CC-BY) license (http:/ / creativecommons.org/licenses/by/4.0/). 